\title{
TUBERCULOMA IN PREGNANCY
}

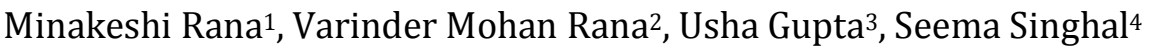

\section{HOW TO CITE THIS ARTICLE:}

Minakeshi Rana, Varinder Mohan Rana, Usha Gupta, Seema Singhal. "Tuberculoma in Pregnancy". Journal of Evolution of Medical and Dental Sciences 2015; Vol. 4, Issue 23, March 19; Page: 4049-4051,

DOI: $10.14260 /$ jemds/2015/584

\begin{abstract}
Tuberculoma is second only to neoplastic lesions as a cause of raised intracranial tension. Tuberculosis is quite common in developing countries. It is therefore quite likely that a pregnant patient with a history of convulsions may have tuberculoma. We had a similar case of term pregnancy with history of convulsions. CT scan clinched the diagnosis of tuberculoma. The patient delivered per vaginum. The patient was put on anti - tubercular drugs for 18 months and lesions disappeared on repeat CT.
\end{abstract}

KEYWORDS: Tuberculoma, Pregnancy, Computerized tomography, ATT, GTCS.

INTRODUCTION: Tuberculosis remains an important public health problem in developing countries and causes significant morbidity and mortality. Tuberculosis in women may be pulmonary or extra pulmonary. Extra pulmonary tuberculosis may be of lymph node, genital tract or CNS. Tuberculosis of genital tract is an important cause of female infertility. The incidence of tuberculosis in pregnancy ranges between 1-2\% amongst hospital deliveries in the tropics, being confined predominantly to the underprivileged sections of society. ${ }^{1}$

Most common manifestation of central nervous system (CNS) tuberculosis is meningitis and uncommonly can also present as tuberculoma. Tuberculosis of central nervous system accounts for about $5 \%$ of extra pulmonary cases. ${ }^{2}$ Tuberculoma presents as one or more space occupying lesion and usually causes seizures and focal signs. We report a case of intra-cerebral tuberculoma in pregnancy.

CASE REPORT: A 20 - year - old primigravida with 9 months amenorrhea and in labour was referred from some Delhi Hospital with history of three episodes of generalized tonic clonic convulsions since morning. There was history of headache for four months with weakness of left half of body, similar episodes of GTC convulsions 15 days back. She had no history of trauma or head injury in the past. There was history of dengue fever and meningitis two years back. On examination her general condition was unsatisfactory. The patient was conscious but was drowsy. She was oriented and cooperative. She was afebrile. Her pulse was 90 per minute and she was normotensive. There was no tachypnoea. There was no pallor. There was no pedal oedema. Her pupils were equally reacting to light. Fundus examination was normal. There was no facial paresis and her facial sensations were normal. Power was assessed in both the upper and lower limbs and was 5/5. Knee jerks were normal.

On obstetric examination, the uterus was term size with cephalic presentation, mild uterine contractions were present. The fetal heart rate was regular, 140 per minute. Per vaginal examination revealed that cervix was 50-60\% effaced, os 3-4 cm dilated and pelvis was normal in shape and size.

Complete blood count was normal. Other routine investigations were also normal. CECT head showed conglomerate brain enhancing lesion involving right temporo-parietal hemisphere with perilesional oedema and significant midline shift to left side suggestive of inflammatory granulomatous lesion most likely Tuberculoma. 


\section{CASE REPORT}

FIGURE 1: Showing CECT head with conglomerate contrast enhancing lesion involving right temporo - parietal hemisphere.

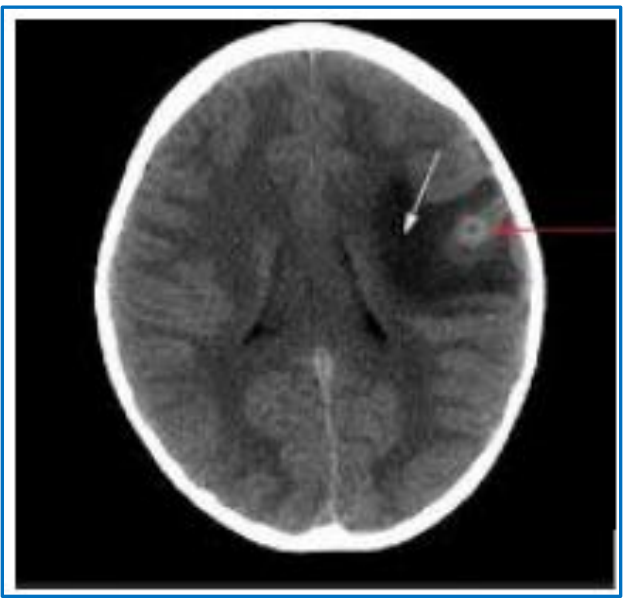

\section{Fig. 1}

Patient delivered within 5 -6 hrs of admission and based on clinical and CECT findings, a diagnosis of tuberculoma was made and patient was started on anti-tubercular drugs for 18 months. Patient was followed for 18 months and there were no convulsions during treatment period. Repeat CT scan showed disappearance of the lesion.

DISCUSSION AND CONCLUSION: Tuberculoma is second only to neoplastic lesions as a cause of raised intracranial pressure. It may occur both in supratentorial and infratentorial compartments. Patients may present with signs and symptoms of raised intracranial pressure or with localizing signs and symptoms. ${ }^{3}$ The diagnosis is more difficult during pregnancy. More commonly eclampsia becomes the presumptive diagnosis in patients with convulsions during pregnancy, unless other differential diagnosis are kept in mind and specifically looked for. ${ }^{4}$ Patients with tuberculoma are usually normotensive and do not have proteinuria. CT scan or MRI is usually necessary and clinches the diagnosis with proper clinical correlation. ${ }^{5}$ On CT scan a circumscribed focal granulomatous mass of tubercular origin affecting the brain parenchyma and acting as a space occupying lesion is designated as a tuberculoma. It can occur as a single or multiple lesions, varying in size from less than one centimetre to several centimetres in diameters affecting any part of brain. ${ }^{6}$ Treatment of CNS tuberculosis is with anti-tubercular drugs for at least 18 months.

\section{REFERENCES:}

1. Dutta DC. Medical and Surgical illness complicating Pregnacy. In: Konar Hiralal, editor. Text book of Obstetrics. Calcutta: New Central Book Agency (P) Limited 1998. P. 277-323.

2. Ravinglione MC, O Brien RJ. Tuberculosis. IN: Fauci AS, Joseph MB, Braunwald E, Kasper DL, Issel bacher KJ Hauser SL etal, editors Harisons Principles of Internal Medicine. Singapore: McGraw-Hill 1998. p. 1004-14.

3. Thomas ND. Tuberculosis. In: Harrison's principles of internalmedicine, New York, McGrawHill. 1991; 1: 637. 


\section{CASE REPORT}

4. Reimers D. Tuberculosis in pregnancy. Prax Klin Pneumol 1983; 37(Suppl). 455-7.

5. Schabet M. Cerebral tuberculoma in pregnancy. Nervenarzt 1988; 59(7): 405-7.

6. Banerjee AK, Chopra JS, Uncommon neurological presentations of tuberculoma. Clin Neurol Neurosurg 1979; 81: 122-8.
AUTHORS:
1. Minakeshi Rana
2. Varinder Mohan Rana
3. Usha Gupta
4. Seema Singhal

\section{PARTICULARS OF CONTRIBUTORS:}

1. Senior Resident, Department of Obstetrics \& Gynaecology, Lady Hardinge Medical College, New Delhi.

2. Junior Resident, Department of Medicine, Lady Hardinge Medical College, New Delhi.

3. Director Professor, Department of Obstetrics \& Gynaecology, Lady Hardinge Medical College, New Delhi.

FINANCIAL OR OTHER

COMPETING INTERESTS: None
4. Associate Professor, Department of Obstetrics \& Gynaecology, Lady Hardinge Medical College, New Delhi.

\section{NAME ADDRESS EMAIL ID OF THE CORRESPONDING AUTHOR:}

Dr. Minakeshi Rana,

H. No. 24, Lane51,

Greater Kailash,

Jammu.

E-mail: minakeshirana76@gmail.com

Date of Submission: 20/02/2015.

Date of Peer Review: 23/02/2015.

Date of Acceptance: 07/03/2015.

Date of Publishing: 19/03/2015. 